\section{Review of Singer: Animal Liberation (second edition)}

\author{
David DeGrazia \\ George Washington University
}

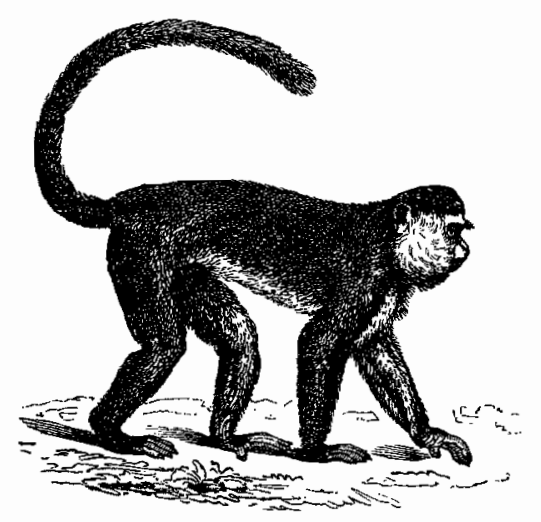

The publication of the second edition of Peter Singer's Animal Liberation invites us to revisit the contributions of the philosopher who, more than anyone else, made the discussion of animal ethics intellectually respectable. Animal Liberation remains important not only for philosophers and activists working in this area but also for those interested in what a philosophical book can do. I say this for five reasons, which summarize my praise for the book.

First, Animal Liberation (hereafter, ' $A L$ ') is extremely well written. To my mind, no philosopher writing in the English language today does it better than Singer. He demonstrates in $A L$, as always, how to express philosophical ideas clearly and concisely. ${ }^{1}$ Second, Singer's arguments are exceedingly cogent. At times the economy of his expression leads superficial readers to think he has failed to defend a point that needs defense (e.g., why sentience is necessary for moral status), or argued a thesis he has not (e.g., that the lives of all animals are equally valuable). A third virtue of $A L$ is its wealth of factual information relevant to the moral issues confronted-particularly animal research and factory farming. This attention to factual detail is instructive because

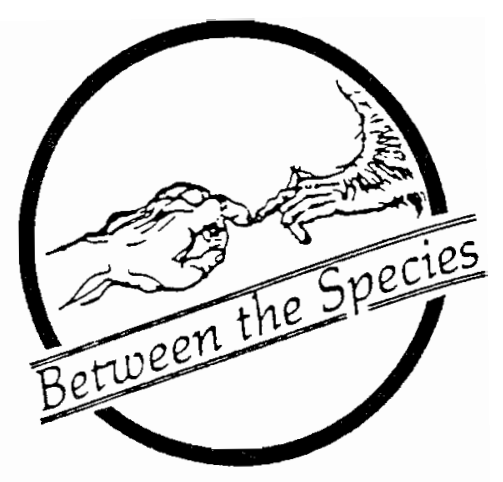

philosophers commonly neglect factual matters relevant to the moral issues they tackle. The second edition is particularly important for updating the reader fifteen years on the state of the practices under scrutiny. $A L$ also serves as an example of the impact moral philosophy can have on the world. The book was one of the most significant catalysts for the modern animal rights movement. And it helped change the world precisely because it was (1) clearly written, so that nonphilosophers could learn from it, (2) cogently argued, so that philosophers might (eventually) come around to taking the issues seriously, and (3) bursting with relevant factual information, so that neither laypersons nor philosophers could continue to hide behind comfortable misconceptions.

But the very attempt to change the world with reasoned arguments presupposes the Socratic attitude that philosophy is for " $[t]$ hinking through, critically and carefully, what most of us take for granted" ( $A L$, 236). ${ }^{2}$ This brings us to a fifth way in which $A L$ shows what a philosophy book can do: It can offer intellectually honest criticism of the profession itself. Singer exposes the widespread failure of moral philosophers to perform philosophy's critical task, noting how many leading scholars evade inevitable conclusions and lower their standards of argumentation when considering the status of animals. For example, Rawls, confronted with the fact that many

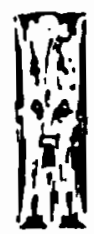


humans, like animals, lack the sense of justice necessary (in his view) for the possession of moral rights, pleads, "I cannot examine the problem here, but I assume that the account of equality would not be materially affected" (quoted in $A L, 240$ ). ${ }^{3}$ In the remainder of this review I will examine the text chapter by chapter, before criticizing several points of Singer's argumentation.

Chapter 1 contains the main philosophical argument. After explaining that underlying the rejection of racism and sexism is some fundamental moral principle of equality, Singer gives it the endorsement of the best work of his profession:

the leading figures in contemporary moral philosophy have shown a great deal of agreement in specifying as a fundamental presupposition of their moral theories some similar requirement that works to give everyone's interest equal consideration $(A L, 5)$.

Because many animals have interests, it is possible to take animals into account in moral decision-making. And because there is no apparent reason not to take animals' interests into account-certainly none that would exclude all animals while protecting all humans-animals with interests deserve equal consideration. In a frequently misunderstood passage, Singer (quite clearly, I think) explains that the fact of having interests is conceptually necessary and sufficient for moral considerability and that this entails a de facto criterion of sentience:

The capacity for suffering - or more strictly, for suffering and/or enjoyment or happinessis not just another characteristic like the capacity for language or higher mathematics .... By saying that we must consider the interests of all beings with the capacity for suffering or enjoyment Bentham does not arbitrarily exclude from consideration any interests at all-as those who draw the line with reference to the possession of reason or language do. The capacity for suffering and enjoyment is a prerequisite for having interests at all .... A stone does not have interests because it cannot suffer. Nothing that we could do to it could possibly make any difference to its welfare. The capacity for suffering and enjoyment is, however, not only necessary, but also sufficient for us to say that a being has interests-at an absolute minimum, an interest in not suffering [sentence added in this edition] $(A L, 7-8)$.

Singer sidesteps the normative debate between the utilitarianism and rights theorists because settling the question of rights is unnecessary to the defense of animal liberation $(A L, 8)$. He goes on to provide a series of arguments (somewhat updated from the first edition) against the odd claim that animals have no interests, though it is noteworthy that he ignores Frey's rather sophisticated arguments to this conclusion. ${ }^{4}$ Having argued that animals feel pain and that there is no justification for regarding human pain as more important that animal pain, Singer explores the implications. In doing so, he emphasizes equal consideration, which he takes to be virtually uncontestable, rather than utilitarianism, the specific ethical theory to which he subscribes:

So far as this argument is concerned nonhuman
animals and infants and retarded humans are
in the same category; and if we use this
argument to justify experiments on nonhuman
animals we have to ask ourselves whether we
are also prepared to allow experiments on
human infants and retarded adults; and if we
make a distinction between animals and these
humans, on what basis can we do it, other than
a bare-faced-and morally indefensible-
preference for our own species $(A L, 16)$ ?

Before concluding the chapter, Singer explains that equal consideration does not entail that all lives are of equal value, thereby highlighting the important distinction between equal consideration and equal treatment. (Because the case for liberating animals from our major animal-exploiting institutions can be made by appeal to suffering alone, he considers this issue secondary.) Equal consideration entails that "beings who are similar in all relevant respects have a similar right to life-and mere membership in our own biological species cannot be a morally relevant criterion for this right" $(A L, 19)$. Unlike S. F. Sapontzis, but like Tom Regan and James Rachels, Singer ends up with a view that implies that human lives are ordinarily more valuable than animal lives: 
While self-awareness, the capacity to think ahead and have hopes and aspirations for the future, the capacity for meaningful relations with others and so on are not relevant to the question of inflicting pain-since pain is pain ... - these capacities are relevant to the question of taking life. It is not arbitrary to hold that the life of a self-aware being, capable of abstract thought, of planning for the future, of complex acts of communication, and so on, is more valuable than the life of a being without these capacities $(A L, 20)$.

Chapter 2 is a discussion of the use of animals in research. The wealth of details (including much that is new to this edition), the doubts cast on the usefulness of most research, the descriptions of alternatives to research, and the exposure of the disingenuous way in which researchers have sold themselves to the public, all add up to as convincing a case against animal research as I have read. Singer summarily tells us that of "the tens of millions of experiments performed, only a few can possibly be regarded as contributing to important medical research" $(A L, 40)$. His conclusion about psychological research is particularly scathing:

what is so disturbing about the examples of research given above is that despite the suffering the animals have gone through, the results obtained, even as reported by the experimenters themselves, are trivial, obvious, or meaningless. The conclusions of the experiments cited above show ... that experimental psychologists have put a lot of effort into telling us in scientific jargon what we knew all along, and what we could have found out in less harmful ways with little thought-and these experiments were supposedly more significant that others that did not get published $(A L, 49-50)$.

Among the details presented are many that are striking-e.g., the fact that U. S. regulations do not even cover mice and rats, the most commonly used species.

Later in the chapter Singer confronts the question of whether the use of research animals is ever justified. His answer exemplifies once more the prudent strategy of relying on equal consideration instead of the more specific and controversial standpoint of utilitarianism:
Would we be prepared to let thousands of humans die if they could be saved by a single experiment on a single animal?

This question is, of course, purely hypothetical. There has never been and never could be a single experiment that saved thousands of lives. The way to respond to this hypothetical question is to pose another: Would the experimenters be prepared to carry out their experiment on a human orphan under six months old if that were the only way to save thousands of lives $(A L, 81)$ ?

His utilitarian colors do appear later, however. In response to the above question, he states that it "will not do to say "Never!"” $(A L, 85)$, before elaborating:

I do not believe that it could never be justifiable to experiment on a brain-damaged human. If it really were possible to save several lives by an experiment that would take just one life, and there were no other way those lives could be saved, it would be right to do the experiment. But this would be an extremely rare case. Certainly none of the experiments described in this chapter could pass the test $(A L, 85)$.

This passage fairly clearly establishes Singer's view as act-utilitarian, a point to which I will return later.

Singer's good sense is revealed in the way in which he stands back from the institution of animal research and views it in its proper perspective. He ridicules, for example, our ineffectual fight against cancer:
Although tens of thousands of animals have been forced to inhale tobacco smoke for months and even years, the proof of the connection between tobacco use and lung cancer was based on data from clinical observations in human beings. The United States government continues to pour billions of dollars into research on cancer, while it also subsidizes the tobacco industry $(A L, 88)$.

At the end of the chapter the big picture is more-and more painfully_-evident:

the major health problems of the world largely continue to exist, not because we do 
not know how to prevent disease and keep people healthy, but because no one is putting enough effort and money into doing what we already know how to do. The diseases that ravage [the poor around the world] are diseases that, by and large, we know how to cure .... It has been estimated that 250,000 children die each week around the world, and that one quarter of these deaths are by dehydration caused by diarrhea. A simple treatment, already known and needing no animal experimentation, could prevent the deaths of these children. Those who are genuinely concerned about improving health care would probably make a more effective contribution to human health if they left the laboratories and saw to it that our existing stock of medical knowledge reached those who need it most $(A L, 92)$.

The third chapter, which discusses factory farming, continues the onslaught of horrifying details depicting the realities of our treatment of animals. It is updated from the first edition in several respects. For example, it discusses Marian Dawkins' recent efforts to use behavioral evidence to establish rigorously the preferences of animals presented with certain choices $(A L, 117)$. It also highlights some progressive suggestions by the European Parliament on how to improve the welfare of animals on factory farms $(A L$, 143), and describes how Sweden is leading the way with reforms $(A L, 144)$. No description of this chapter could be complete without offering some sense of the detailed account it provides of factory farming. Here is one sampling, which describes the castration of bulls:

Anesthetics are generally not used. The procedure is to pin the animal down, take a knife, and slit the scrotum, exposing the testicles. You then grab each testicle in turn and pull on it, breaking the cord that attaches to it; on older animals it may be necessary to cut the cord $(A L, 145)$.

A second passage describes ritual slaughter in the U. S.:

[What follows] is the result of a combination of the requirements of ritual slaughter and of the Pure Food and Drug Act of 1906, which for sanitary reasons stipulates that a slaughtered animal must not fall in the blood of a previously slaughtered animal .... [A] nimals being ritually slaughtered in the United States may be shackled around a rear leg, hoisted into the air, and then hang, fully conscious, upside down on the conveyor belt for between two and five minutes-and occasionally much longer if something goes wrong on the "killing line"-before the slaughterer makes his cut $(A L, 154)$.

Chapter 4, which concerns the moral issue of vegetarianism, contains some points of philosophical and factual interest. Singer begins by arguingprobably (in part) against the position of Frey ${ }^{5}$-that while it may be logically consistent to oppose the present conditions of factory farming while continuing to eat factory-farmed meat, to do so would be psychologically very difficult and probably impractical $(A L, 159)$. For those who, like Frey, wonder whether one's own boycotting efforts can be known to have any actual effect on the industry, this is a serious issue-that is, if one is a utilitarian, for then one justifies one's actions in terms of expected consequences. Singer rightly notes that "none of the great movements against oppression and injustice could have existed if their leaders had made no efforts until they were assured of success" $(A L, 163)$. (This fact, it seems to me, provides strong grounds for some type of moral rule requiring participation in cooperative efforts needed to defeat serious injustices. It is not entirely clear that act-utilitarianism vindicates such a rule; if not, I take that to be a deficiency of act-utilitarianism.) But Singer also thinks our individual efforts do reduce demand, thereby saving some animals from suffering and death, even if our actions are not part of a collective effort that succeeds in abolishing factory farming ( $A L, 163-164)$.

On the topic of traditional farming, Singer notes that even these comparatively humane methods involve "castration, separation of mother and young, breaking up of social groups, branding, transportation to the slaughterhouse, and finally slaughter itself" $(A L, 160)$. Even if animals could be reared without these causes of suffering, that would be possible only on a small scale, resulting in vastly higher meat prices and the impossibility of feeding our huge urban populations $(A L, 160)$. From a practical standpoint, this obviates 
the issue of whether the painless killing of animals for food is justified $(A L, 160)$.

Chapter 5, an engaging history of speciesism, will have to be passed over.

Chapter 6, "Speciesism Today," contains excellent arguments against common rationalizations for the exploitation of animals. I include two examples. To counter the claim that life in a factory farm is preferable to the dangers awaiting animals in the wild, Singer argues the following:

Factory farm animals cannot walk, run, stretch freely, or be part of a family or herd. True, many wild animals die from adverse conditions or are killed by predators; but animals kept in farms do not live for more than a fraction of their normal life span either. The steady supply of food is not an unmitigated blessing, since it deprives animals of their most basic natural activity, the search for food. The result is a life of utter boredom, with nothing at all to do but lie in a stall and eat $(A L, 227)$.

More likely to be overlooked is the fact that the choice between living on factory farms and living in the wild is illusory; abolishing factory farms would not mean returning animals to their natural habitat. It would mean that animals would no longer be bred for factory farms $(A L, 227)$.

Nor can it be argued that animals are better off factory-farmed than nonexistent; to bring them into existence with that quality of life is no benefit to them, "but rather a great harm" $(A L, 229)$. Singer concedes that animals with no sense of the future might be benefited by being brought into existence, if they live on free-range farms and are killed quickly and painlessly. But even to those who would invoke such ingenious grounds for selective meat-eating, Singer has a brilliant retort:

If it were good to bring things into existence then presumably, other things being equal, we ought to bring as many humans as possible into existence too; and if to this we add the view that human lives are more important than the lives of animals-a view the flesh-eater seems sure to accept-then the argument may be turned on its head .... Since more humans may be fed if we do not feed our grain to livestock [as Singer demonstrated earlier], the upshot of the argument is, after all, that we ought to become vegetarians $(A L, 230)$ !

$A L$ concludes with Appendices for further reading, tips on getting by without the products of animal exploitation, and organizations for animal welfare.

Let me turn at this point to criticisms of the book. My criticisms may take us deeper into philosophical theory than Singer wished to go in $A L$; indeed, Singer indicates that he does not regard his book as one of academic philosophy $(A L, \mathrm{x})$. Nevertheless, he also says, "I have come across no insurmountable objections, nothing that has led me to think that the simple ethical arguments on which the book is based are anything but sound" $(A L, \mathrm{xi})$. This would seem to make it fair game to subject his "simple arguments" to criticisms at any level of sophistication.

To begin with, Singer fails to address respectable criticisms of equal consideration, and has not explained, in any detail, what equal consideration amounts to. One challenge, which is widely held and might be called "the argument from social bondedness," is well stated by Mary Midgley. In a qualified endorsement of the idea that the needs of those closest to us have moral priority over the needs of those less close, she invokes social bondedness: "The special interests which parents feel in their own children is not a prejudice, nor is the tendency which most of us would show to rescue, in a fire or other emergency, those closest to us." 6 By way of analogy she argues that a preference for our own species is acceptable but has limits, in no way justifying the complete dismissal of animals' interests. Thus, her view accommodates some degree of unequal consideration.

While, like Singer, I am a champion of equal consideration, I think far more needs to be said about this principle to provide a philosophically adequate defense of it. Midgley's strongest case is priority given to one's children. A Singerian response would be that the rightness of such priority is explicable by the greater long-term efficiency of such partiality, since children are better cared for if parents focus greater concern on their own. However, many clear-thinking philosophers will not be satisfied by this account, believing that the nature of the relationship of parent to child justifies preferential treatment. Like W. D. Ross, they will insist that, even if long-term utility vindicates such discrimination (so that equal consideration is also 
vindicated), this fact is simply fortuitous for the champion of equal consideration; the morality of giving priority to one's children is not contingent on its efficiency. ${ }^{?}$

A second challenge to equal consideration is what I call the "sui generis view." Justifications for what counts as a morally relevant characteristic or fact about a being, the argument goes, have to end somewhere; logic alone cannot decide what counts as relevant. The champion of equal consideration and her opponent simply differ on what facts are relevant. Some examples will clarify the general point being made about ethical justification.

Rationalists believe that reasons justifying correct moral judgments can be provided up to the point at which it can be shown that denying the judgment would involve a logical error (or perhaps some other form of irrationality). Others believe that self-interest is the only secure anchor for an ethical position. Still others hold that neither formal rationality nor self-interest is capable of grounding moral judgments, but that there are certain objective moral axioms that one either recognizes or does not. ${ }^{8}$ For the "sui generis inegalitarian," being human just is, sui generis, a morally relevant characteristic that grounds preferential treatment. The argument for the relevance of being human goes no further than that; it is no contradiction to hold the opposite view. While many champions of equal consideration invoke traits that cut across species lines (as Singer and I do), no logical demonstration is ever (or could be) offered that species membership per $s e$ is morally irrelevant. Singer nearly confronts this view in $A L$, but ends up saying "any satisfactory defense of the claim that all and only human beings have intrinsic dignity [ i.e., deserve greater consideration] would need to refer to some relevant capacities or characteristics that only human beings have" $(A L, 239)$. As a point of philosophical logic, it is false that one must invoke traits beyond being human to claim that humans deserve greater consideration. I tentatively agree that no satisfactory defense of unequal consideration would fail to adduce further characteristics, but Singer seems blind to issues that an adequate defense of equal consideration would treat. In fact, until recently, Singer apparently thought equal consideration was a logically necessary feature of moral language. ${ }^{9}$

Singer also fails to explain what equal consideration amounts to. What is the criterion for one's interests being identical to another? An answer is needed to determine, in some difficult cases, whether certain interests of different beings must be given equal consideration. For example, Singer believes that different lives may have different values; he states that it "is not arbitrary to hold that the life of a self-aware being, capable of abstract thought, of planning for the future, of complex acts of communication, and so on, is more valuable than the life of a being without these capacities" $(A L, 20)$. I assume this means that the life of a normal adult human and that of a mouse are not to be given equal consideration, for, if one must choose between them, one should, on this view, save the human. The likely response is that they need not be given equal consideration because what is at stake is not the sametwo different interests, or bundles of interests, are being compared. Fine, but what determines whether two interests, or sets of interests, are identical, or sufficiently similar that equal consideration applies to them? This issue is important also in considering the interest of not being confined. Is a normal human's interest in not being confined such that it should be given equal consideration to, say, a goldfish's interest is not being confined? The answers, at least when considering mammals might have some implications for animal research. ${ }^{10}$

We noted above that Singer is an act-utilitarian. (This view usually lurks in the background of $A L$, since, again, Singer puts most of his arguments' normative weight on equal consideration.) This is not the place to review the many objections lodged against actutilitarianism (AU), but I will briefly mention a few. As we have seen, it is at least not obvious that $\mathrm{AU}$ vindicates a rule requiring cooperative efforts against major injustices, or preferential treatment toward one's own children. Far more obvious is that these should be vindicated. Moreover, AU seems to require in certain, perhaps very rare or even hypothetical circumstances, that a judge knowingly condemn an innocent person to death, that one kill an innocent person to save two (not a thousand) people, that one even rape or torture a child when, using one's best estimates, doing so would cause more (not necessarily far more) good than harm.

Defenders of AU have come up with clever responses to such objections. Sometimes they vindicate the intuition that a particular action is wrong but argue that $A U$ does not endorse it. In some cases it is claimed that the situation described in the objection will never occur in the real world. For example, it might be said 
that maximizing utility will never justify enormously unequal distributions of basic goods to different groups of people, some of whom are left in misery. While such a situation is imaginable, they say, utilitarians are only responsible for the real world.

But notice, first, that in such cases the wrongness of such actions usually seems far more certain than any ethical theory. So, if AU vindicates the seemingly right action in the end, that is, as it were, lucky for AU. Second, would it not be strange if AU were true for our world but false for worlds that are, after all, not so different from ours? (Remember that, in many cases, it is unclear whether AU requires a seemingly wrong act in our world, or only in other worlds.) The point is that the efforts to defend $\mathrm{AU}$ against objections like these seem so strained that one wonders why anyone bothers. What is so great about AU?

Before answering, it is important to note that Singer does not think moral intuitions have any credibility, that they are anything but appeals to bias. ${ }^{11}$ (By "intuition" I mean a judgment that is justified by its seeming to be correct, whether or not further argument could justify it.) One might wonder what could reasonably overrule our strongest reflective moral convictions (which, by definition, have been examined for possible bias). ${ }^{12}$ Now, surely there is one possible foundation of morality that, if it does its job, provides our answer: reason (say, appeal to facts and logic). If reason can demonstrate that (1) we should be moral (solving the "is-ought problem") and that (2) we should follow a particular ethical theory, then there is no need to appeal to intuition. But rationalism in this sense has been widely rejected.

However, Singer believes that reason provides a foundation for ethics and, specifically, AU. His metaethics is based on the work of R. M. Hare. ${ }^{13}$ Singer is aware of what is at stake: "If [Hare's argument is right], his work must rank as the most important result of recent ethics, perhaps even as the culmination of all Western moral philosophy." ${ }^{14}$ Hare's famous argument is based on the claim that moral language is necessarily prescriptive and universal (the latter feature underlying equal consideration). I cannot outline his ingenious case here or take up the major objections against it. (I must confess, though, that when a philosopher announces the discovery of a rational foundation for ethics and for a particular moral theory, I feel almost as I do when I hear of a "proof" for the existence of God.) But I do think that some of the objections are successful. ${ }^{15}$ In fairness to Singer, since I cannot explore objections here, let me just say that if he is right about Hare's contribution, then appeals to intuition in ethics are unwarranted and AU is correct. But if Hare's case fails-in the absence of a rational demonstration for the truth of some moral theory - we seem to be left with little reason to castigate the discriminating use of intuition in ethics, and just as little reason to accept $\mathrm{AU}$, with all of its counterintuitive implications.

\section{Notes}

${ }^{1}$ Even greater skill at expressing complex ideas clearly is demonstrated in his Marx (Oxford University Press, 1980) and Hegel (Oxford University Press, 1983).

${ }^{2}$ An outstanding example of Singer's rising to this task in found in his "Famine, Affluence, and Morality," in Thomas A. Mappes and Jane S. Zembaty, eds., Social Ethics: Morality and Social Policy (New York: McGraw Hill, 1977), pp. 315-322. Here Singer argues from modest ethical premises to the conclusion that our complacent attitudes about famine are entirely unjustified.

${ }^{3}$ In the second edition, however, Singer notes that moral philosophy has gone a long way toward throwing off its "ideological blinkers." Animal liberation has received a great deal of academic attention and today many ethics courses challenge students to think through the issues.

${ }^{4}$ R. G. Frey, Interests and Rights: The Case Against Animals (Oxford: Clarendon, 1980). Perhaps Singer ignored Frey's view because he thought it too farfetched or too complicated to justify entering into.

${ }^{5}$ R. G. Frey, Rights, Killing, and Suffering: Moral Vegetarianism and Applied Ethics (Oxford: Blackwell, 1983).

${ }^{6}$ Animals and Why They Matter (Athens, Georgia: University of Georgia Press, 1984), p. 102.

${ }^{7}$ Ross argues only against the utilitarian account, not against equal consideration in The Right and the Good (Oxford: Oxford University Press, 1930), ch. 2.

${ }^{8}$ See Ross' classic defense of a set of self-evident prima facie duties in The Right and the Good. See also Tom L. Beauchamp, "Problems in Justifying Research on Animals," in National Institutes of Health, National Symposium on Imperatives in Research Animal Use: Scientific Needs and Animal Welfare (NIH Publication No. 85-2746, 1985), p. 87.

${ }^{9}$ See. e.g., Practical Ethics (Cambridge: Cambridge University Press, 1979), pp. 10-11. 
${ }^{10}$ I grapple with this surprisingly complex issue in "Equal Consideration and Unequal Moral Status" (manuscript under review).

${ }^{11}$ He does, however, sometimes use them. See, e.g., $A L$, 228 and 229.

${ }^{12}$ For an attempted refutation of extreme anti-intuitionism, see my Interests, Intuition, and Moral Status (a 1989 Georgetown University dissertation), ch. 3.

${ }^{13}$ R. M. Hare, Moral Thinking: Its Levels, Method, and Point (Oxford: Clarendon, 1981).

14 "Reasoning towards Universalizability," in Douglas Seanor and N. Fotion, eds., Hare and Critics: Essays on Moral Thinking (Oxford: Clarendon, 1988), p. 147. Actually, in this article Singer suggests that Hare's case needs some supplemental reasoning, which he attempts to provide. In doing so, he notes that "placing a restriction on universalizability does not seem to involve an inconsistency in any strict logical sense" (p. 157) (see discussion of the "sui generis view" above); he thinks instead that such a restriction is arbitrary. While he imagines a counter to the charge of arbitrariness (pp. 158-159), the interlocutor is not very resourceful. In any event, Singer's supplemental argumentation cannot save Hare's theory if the latter fails for other reasons, as I (and most other moral philosophers) think.

${ }^{15}$ For some weighty arguments against Hare's view, see R. B. Brandt, "Act-Utilitarianism and Metaethics,"Thomas Nagel, "The Foundations of Impartiality," and Bernard Williams, "The Structure of Hare's Theory," in Hare and Critics.

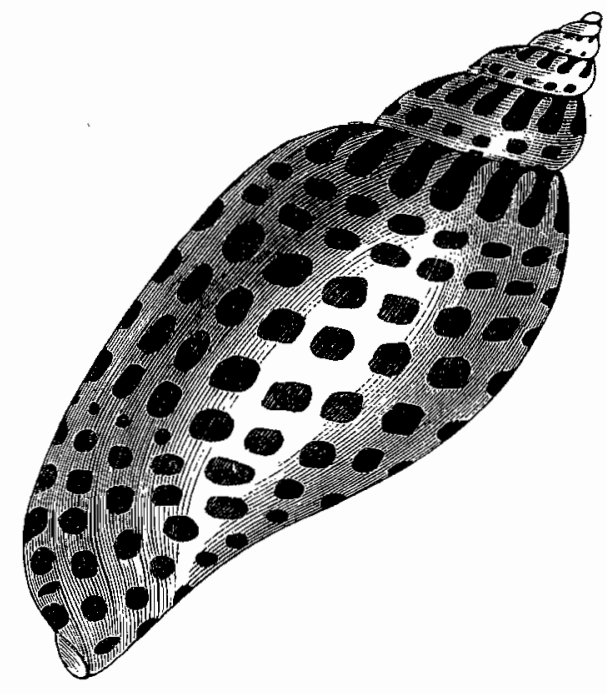

\section{A Response to David DeGrazia}

\section{Peter Singer Monash University}

My first reaction, on reading David DeGrazia's review of the second edition of Animal Liberation, was to applaud. He has located the strengths and weaknesses of the book with a rare precision. If his praise is too generous, I shall leave it to others to take him to task over that. To me, it is particularly pleasing because it is not the praise of an uncritical admirer. Nor did my urge to applaud fade away when I turned to the final, most critical, section of the review, for here I found DeGrazia's criticisms do indeed point to aspects of the book's argument that are, at best, incompletely developed.

DeGrazia is right to say that some of his criticisms go more deeply into philosophical theory than I wanted to do in $A L$. When I came to write the second edition, I knew that there was now a mass of sophisticated philosophical literature on the topic that had not existed when I wrote the first edition. At first I planned to respond to it, but I soon realized that if I were to do so, I would be writing a different, and much less readable, book. That was something I did not want to do. I vaguely intend to write a comprehensive "reply to my critics" on some future occasion; meanwhile other projects fill my time, projects more stimulating and, I think, more fruitful than the tedious prospect of exposing the flaws in a volley of objections, some of which are of interest only insofar as they provide evidence of the lengths to which intelligent people with philosophical training can go in order to avoid the need to change their diet.

I do not, however, include in the scope of that last sentence the difficulties to which DeGrazia points in the final part of his review. The matters to which he

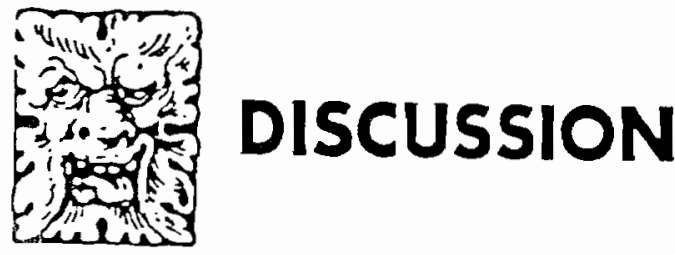

